\title{
Pica Practices among Pregnant Women Are Associated with Lower Hemoglobin Levels and Pregnancy Outcome
}

\author{
Fahimeh Khoushabi ${ }^{*}$, Parvin Ahmadi1, Mohammad Reza Shadan², Azadeh Heydari1, \\ Ali Miri', Maryam Jamnejad ${ }^{3}$ \\ ${ }^{1}$ School of Health, Zabol University of Medical Sciences and Health Services, Zabol, Iran \\ ${ }^{2}$ School of Medicine, Zahedan University of Medical Sciences and Health Services, Zahedan, Iran \\ ${ }^{3}$ School of Health, Tehran University of Medical Sciences and Health Services, Tehran, Iran \\ Email: fyasiny@yahoo.com
}

Received 2 June 2014; revised 2 July 2014; accepted 25 July 2014

Copyright (C) 2014 by authors and Scientific Research Publishing Inc.

This work is licensed under the Creative Commons Attribution International License (CC BY).

http://creativecommons.org/licenses/by/4.0/

(c) (i) Open Access

\section{Abstract}

Pica is an eating disorder in which non-nutritional objects are frequently eaten, and may have serious side effects for both the mother and neonate. The aim of this study was to determine the pica and its association with biochemical profiles of pregnant women and its relation to pregnancy outcome. A prospective cohort study was conducted in five health care centers in Zahedan City, Iran, in 2011-2012. Samples of pregnant women $(n=200)$ in the age groups 18 - 40 years were selected for this study and interviewed using a questionnaire. Maternal biochemical profiles (hemoglobin and ferritin) during pregnancy, mean gestational age and pregnancy outcome namely height, weight, and head circumferences of neonates were compared to pregnant women who reported pica (pica group) and women who did not (without pica group). The results showed pica prevalence categorized by substance as follows: clay $(23.3 \%)$, ice $(53.7 \%)$, ice and freezer frost $(11.5 \%)$ and other substances $(\mathbf{1 1 . 5 \% )}$. Women in pica group had lower hemoglobin levels during the three trimesters of pregnancy than without pica group. Head circumferences of neonates in pica groups were significantly lower than those of without pica groups $(31.0 \pm 0.6 \mathrm{vs} .34 .0 \pm 0.2$ respectively). There were no differences in mean birth weight, length, gestational age of infants born to pregnant women from the pica group and without pica group. The findings suggest that the pica practices during pregnancy are associated with lower maternal hemoglobin during the pregnancy periods, and also significantly lower head circumferences of neonates. Dietitians should ask pregnant women with anemia about pica and should counsel pregnant women who report pica.

\section{Keywords}

Pica, Pregnancy Period, Pregnancy Outcome

\footnotetext{
*Corresponding author.
}

How to cite this paper: Khoushabi, F., Ahmadi, P., Shadan, M.R., Heydari, A., Miri, A. and Jamnejad, M. (2014) Pica Practices among Pregnant Women Are Associated with Lower Hemoglobin Levels and Pregnancy Outcome. Open Journal of Obstetrics and Gynecology, 4, 646-652. http://dx.doi.org/10.4236/ojog.2014.411090 


\section{Introduction}

Some pregnant women have a tendency to eat non-food substances. Pica is an eating disorder in which nonnutritional objects are frequently eaten. "Pica" generally refers to compulsive intake of nonfood substances over a sustained period of time [1]-[5]. "Geophagia” specifically refers to compulsive eating of clay or dirt. Other substances that may be consumed include ice or freezer frost (pagophagia) laundry starch, soap, ashes, chalks, paint or burnt matches. However abnormal craving for and intake of some food items, such as corn starch or baking soda, are also considered examples of pica. Food craving and aversions are also very common during pregnancy [6]-[8]. Some of the most commonly craved items are chocolate, citrus fruits, pickles, chips and ice cream. The most common aversions are coffee, tea, fried or fatty foods highly spiced foods, meat and eggs. Food craving may be related to increase energy intake and aversions, and reduce the energy intake [6].

The prevalence of pica according different reports is $0 \%-68 \%$ [5] [9] [10]. Food provides all nutrients for growth, survival and reproduction. Proper nutrition is important during pregnancy and cannot be ignored, because the health and nutritional status of mother and fetus are mainly depended on it. Therefore, understanding about pica, food cravings and aversions during pregnancy is important in ensuring a mother and fetus attains adequate health and nutrition. Despite this, pica's effects are less studied in Zahedanian pregnant women and the outcome of their pregnancies. This study therefore sought to determine the pica and its association with biochemical profiles of pregnant women and its relation to pregnancy outcome.

\section{Materials and Methods}

\subsection{Selection of Area, Health Care Centers and Subjects}

Zahedan, a city situated in Sistan and Baluchestan province, located in the eastern border of Iran. A survey of the thirty health care centers in Zahedan City was done to select the centers for current study. For this study Zahedan City was considered as five zones divisions (north, south, east and west and center). Five health care centers were selected based on their acceptance and willingness to extend support for the study.

The sample size was determined using the formula, $n=z_{1-\alpha / 2}^{2} \cdot p \cdot(1-p) / d^{2}$; where " $n$ " is estimated sample size; "z" is the critical z score based on the desired degree of confidence; "p" is the prevalence rate and is the desired margin of error. Based on Mortazavi and Mohammadian [10], a prevalence rate of $15 \%$ was chosen. Finally, a value of 200 was obtained to represent the target population.

The selected pregnant women were followed up to the third trimester ending in child birth. The inclusion criteria were age group (18 - 40 years) and having common health care visit during the three trimesters of pregnancy in selected women. The pregnant women with diabetes mellitus and cardiovascular disease (CVD) were excluded from the study. The study was approved by Human Ethical Committee of the University of Medical Science. A written consent to participate in the study was obtained from each subject. The study was carried out in the year 2011 to 2012.

\subsection{Questionnaire}

Subjects were asked about their habits of eating clay or dirt, ice, starch, raw rice, or other food or nonfood substances during pregnancy period, and food craving as compulsive and elected ingestion of food substance at least once a day. A food substance was defined as any substance that can be digested and metabolized to give energy and build tissue. Compulsive ingestion of ice raw rice, and starch were classified as pica rather than food craving.

Gestational age was derived from last menstrual period or ultrasound. Maternal blood was analyzed for their hemoglobin and serum ferritin levels during the three trimesters of pregnancy.

\subsection{Assessment of Biochemical Profiles}

Blood samples were collected from pregnant women during the end of each trimester of pregnancy period. The blood was drawn in the morning between 8 and $11 \mathrm{am}$. While in an upright position, the tourniquet was applied for a few seconds, and the venous blood was drawn by means of venipuncture (vacutainer system with multiple sample needles was used). The usual precaution of selecting an easily accessible vein in the anticubital fossa and applying the minimum of venous stasis was observed. A total of $10 \mathrm{cc}$ of blood was collected from each volun- 
teer, and immediately 7 cc of it was transferred into a clean, screw-capped glass tube without anticoagulant and allowed to stand at room temperature until the separation of the serum was started by centrifugation at $4^{\circ} \mathrm{C}$, at a speed of $3000 \mathrm{rpm}$. The separated sera were kept at $-20^{\circ} \mathrm{C}$ until analyses were done. Analysis were done at the Imam Reza Hospital Lab, Mashhad Before the analysis, the separated frozen sera were placed at room temperature to allow thawing, and then were mixed. The analyzed parameters included hemoglobin $(\mathrm{g} / \mathrm{dL})$ and ferritin $(\mathrm{ng} / \mathrm{mL})$. Hemoglobin and Serum ferritin levels were analyzed in the hospital laboratory by cyanomethemoglobin method and Elisa method (on a fully automated Eliza plate reader; Best 2000) respectively.

\subsection{Anthropometric Measurements of Neonates}

Anthropometric measurements of neonates, namely weight, height and head circumferences, were taken within 24 hours after birth, using standard procedure [11] [12]. A beam balance by an accuracy of $50 \mathrm{~g}$ was employed for weighing the infants. Infants were weighted, with minimum clothing while they were restful. The infantmeter was used for measuring the recumbent length of the newborn infant. A lightweight fiberglass infant-meter was used to measure length up to $100 \mathrm{~cm}$. Infants were laid on the board of the infant-meter, which was kept on a flat table. The crown of the head was in the contact with the top end of the device. The knee was extended, so that the feet were at right angles to the leg. The mobile device was then brought in contact with the feet of neonate. This distance between the two right angle devices was measured. The reading was recorded in centimeters with an accuracy of $0.5 \mathrm{~cm}$. The infant's head was steadied and the greatest circumference measured, by placing the fiberglass tape firmly round the frontal bones, just supra-orbital ridges. The tape was passed round the head at the same level, on each side, and laying it over the maximum occipital prominence on the back.

\subsection{Statistical Analysis}

Statistical Package for Social Sciences (SPSS, version 11.5) was used to analyze the data. Frequencies and descriptive statistics (Percentages, means and standard deviations) were generated for variables. The independent $\mathrm{t}$-test was used to determine a difference between the two groups (namely with pica and without pica groups). $\mathrm{P}$ value of less than 0.05 was considered as significance level.

\section{Results}

Demographic characteristics of pregnant women are presented in Table 1. Mean age of pregnant women was $24.3 \pm 5.6$ year. Majority of the women were between the ages of 20 and 29 years (53.9\%). The highest percentages of pregnant women (35\%) had a higher school education, followed by graduation level (30\%). Eighty two percent of pregnant women were housewives. A majority of the subjects (60.4\%) were expecting their first child.

Table 1. Demographic characteristics of pregnant women.

\begin{tabular}{ccc}
\hline Variables & & N (\%) \\
Age & $\leq 19$ & $56(28)$ \\
& $20-29$ & $108(53.9)$ \\
Age (years) (Mean \pm SD) & $\geq 30$ & $36(18)$ \\
& & $24.3 \pm 5.6$ \\
Education & Illiterate & $22(10)$ \\
& Primary & $28(14)$ \\
& Secondary & $70(35)$ \\
Occupation & High school & $60(30)$ \\
& Educated & $164(82)$ \\
Parity & Housewife & $36(18)$ \\
\end{tabular}




\section{Pica Practice, Food Craving and Avoid}

Table 2 presents dietary behaviors among the subjects in terms of pica practice, food craving and avoidance in each trimester. Our finding showed a decrease in prevalence of pica and food craving with increase of each trimester of pregnancy (Table 2). The highest prevalence of pica (17.5\%) observed in the first trimester of pregnancy, while the lowest prevalence (5.6\%) was observed in the third trimester of pregnancy (Table 2).

Common forms of pica practice were ice (53.7\%), clay eating (23.3\%), ice and freezer frost (11.5\%) and other items (11.5\%) (Table 3). Reasons associated with the pica practice included prevention of salivation, nausea and vomiting. Food craving was also a common practice among the pregnant women, with a greater number of the pregnant women (59.7\%) craving for at least one food item during the first trimester of pregnancy. Food craving during the second and third trimesters of pregnancy were $54.2 \%$ and $40.7 \%$ respectively. Foods commonly craved for included sweet items (20.4\%), chocolate (19.7\%), candies (12.6\%), and ice cream (15.3\%). Surprisingly quite a large number of the women (18.7\%) craved for cereal products or foods belonging to starchy roots. The reasons expressed by the pregnant women for food craving were for satisfaction and to prevent either nausea or vomiting. Food avoidance in the first trimester was reported by $50.7 \%$ of the women. In the second trimester, food avoidance was reported among $46.1 \%$ while $47.6 \%$ avoided certain foods in the third trimester. The avoided foods included meat and fish, eggs and milk, green leafy vegetables and cereals, and greasy foods. Reasons associated with food avoidance were the taste or smell of food, feeling of nausea or vomiting and texture of food.

Hemoglobin levels during the three trimesters of pregnancy in pica and without pica groups were as follows; (10.8 g/dL vs. $12.1 \mathrm{~g} / \mathrm{dL}, 10.4 \mathrm{~g} / \mathrm{dL}$ vs. $10.6 \mathrm{~g} / \mathrm{dL}$ and $10.5 \mathrm{~g} / \mathrm{dL}$ vs. $11.8 \mathrm{~g} / \mathrm{dL}$ respectively) (Table 4). Ferritin levels in pica and without pica groups during the three trimesters of pregnancy periods were $64.3 \mathrm{ng} / \mathrm{mL} \mathrm{vs} .70 .3$ $\mathrm{ng} / \mathrm{mL} ; 61.0 \mathrm{ng} / \mathrm{mL}$ vs. $69.1 \mathrm{ng} / \mathrm{mL}$ and $63.9 \mathrm{ng} / \mathrm{mL}$ vs. $70.4 \mathrm{ng} / \mathrm{mL}$ respectively (Table 4).

Anthropometric measurements of the neonates born from mothers with pica and mothers without pica, namely birth weight, height, head circumference and gestational age showed mean $3.211 \mathrm{~kg}, 49.1 \mathrm{~cm}, 31.0 \mathrm{~cm}, 39.2 \mathrm{wk}$ and $3.430 \mathrm{~kg}, 50.0 \mathrm{~cm}, 34.0 \mathrm{~cm}, 39.5$ wk respectively (Table 5).

\section{Discussion}

Finding showed the prevalence of pica in the current study (17.5\%) was a slightly higher than Mortazavi and Mohammadi (15.5\%) [10] and lower than the prevalence of pica that reported by Faustina et al. (47\%) [4].

Table 2. Pica practices, food craving and avoidance among pregnant women during pregnancy periods.

\begin{tabular}{ccccc}
\hline \multirow{2}{*}{ Practices } & & \multicolumn{3}{c}{ Practices during pregnancy periods N (\%) } \\
\cline { 3 - 5 } & & I & II & III \\
\hline \multirow{2}{*}{ Pica } & Yes & $35(17.5)$ & $17(8.3)$ & $11(5.6)$ \\
& No & $165(82.5)$ & $183(91.7)$ & $189(94.4)$ \\
\multirow{2}{*}{ Food craving } & Yes & $119(59.7)$ & $108(54.2)$ & $81(40.7)$ \\
& No & $81(40.3)$ & $91.6(45.8)$ & $95(47.6)$ \\
Food avoidance & Yes & $101(50.7)$ & $92(46.1)$ & $105(52.4)$ \\
\hline
\end{tabular}

Table 3. Pica prevalence by substances $(n=35)$.

\begin{tabular}{|c|c|c|}
\hline Pica substance & $\mathbf{N}$ & Percent \\
\hline Clay & 8 & 23.3 \\
\hline Ice & 19 & 53.7 \\
\hline Ice \& freezer frost & 4 & 11.5 \\
\hline Others & 4 & 11.5 \\
\hline
\end{tabular}


Table 4. Maternal biochemical profiles during pregnancy periods in pregnant women with and without pica.

\begin{tabular}{|c|c|c|c|c|}
\hline \multirow{2}{*}{ Variables } & \multirow{2}{*}{ Trimester of pregnancy } & \multicolumn{2}{|c|}{ Groups } & \multirow{2}{*}{ P value ${ }^{* *}$} \\
\hline & & With pica & Without pica & \\
\hline \multirow{3}{*}{$\mathrm{Hb}(\mathrm{g} / \mathrm{dL})$} & $\mathbf{I}$ & $10.8 \pm 0.8$ & $12.1 \pm 1.1$ & $(0.05)^{*}$ \\
\hline & II & $10.4 \pm 0.6$ & $10.6 \pm 0.1$ & $(0.09)^{\mathrm{NS}}$ \\
\hline & III & $10.5 \pm 1.1$ & $11.8 \pm 0.9$ & $(0.05)^{*}$ \\
\hline \multirow{3}{*}{ Ferritin $(\mathbf{n g} / \mathrm{mL})$} & I & $64.3 \pm 42.0$ & $70.3 \pm 50.3$ & $(0.08)^{\mathrm{NS}}$ \\
\hline & II & $61.0 \pm 22.0$ & $69.1 \pm 45$ & $(0.06)^{\mathrm{NS}}$ \\
\hline & III & $63.9 \pm 29$ & $70.4 \pm 59.0$ & $(0.08)^{\mathrm{NS}}$ \\
\hline
\end{tabular}

${ }^{*} \mathrm{P}<0.05 ;{ }^{\mathrm{NS}}$ : not significant; ${ }^{* *} \mathrm{t}$-test results.

Table 5. Newborn characteristics at delivery in the two groups (with pica and without pica).

\begin{tabular}{|c|c|c|c|}
\hline \multirow{2}{*}{ Variables } & \multicolumn{2}{|c|}{ Groups } & \multirow{2}{*}{ P value ${ }^{* *}$} \\
\hline & With pica & Without pica & \\
\hline Gestational age & $39.2 \pm 0.4$ & $39.5 \pm 1.5$ & $(0.32)^{\mathrm{NS}}$ \\
\hline Birth weight (kg) & $3.211 \pm 0.4$ & $3.430 \pm 0.6$ & $(0.08)^{\mathrm{NS}}$ \\
\hline Birth length (cm) & $49.1 \pm 0.7$ & $50.0 \pm 0.3$ & $(0.62)^{\mathrm{NS}}$ \\
\hline Head circumference $(\mathrm{cm})$ & $33.8 \pm 0.6$ & $34.0 \pm 0.2$ & $(0.11)^{\mathrm{NS}}$ \\
\hline
\end{tabular}

${ }^{*} \mathrm{P}<0.05{ }^{\text {NS }}$ : not significant; ${ }^{* *}$ t-test results.

The prevalence of pica ice was similar to the prevalence of pica ice/freezer reported by Rainville [13] results. But it was much higher than expected, based on the results of previous studies such as Edwards; Cooksey; Corbett; Smulian [2] [3] [8] [14] that included ice and freezer frost as pica substances. The prevalence of pica ice (53.7\%) in this study was lower than the $70 \%$ and $60.9 \%$ that reported by Lopez et al. [15] and Mortazavi and Mohammadi [10]. Food craving and avoidance in our finding were higher than the food craving and avoidance that reported by Nyaruhucha [16].

Comparison between biochemical profiles of pregnant women with and without pica during the three trimesters of pregnancy showed that, except hemoglobin in the second trimester of pregnancy, hemoglobin levels in the pica group were significantly lower than non pica group (Table 4). Similar results reported by Rainville [13] and Kettaneh et al. [17]. In Lopez et al. [15] study there was not a significant difference between hemoglobin levels in pica group and the control group. Ferritin levels during the three trimesters of pregnancy were lower in pica group than the control group, but the difference was not significance, while in Kettaneh et al. [17] and Lopez et al. [15] the mean serum ferritin concentration was found to be higher in the pica groups.

Comparison of outcome of pregnancy in women with pica and without pica are shown in Table 5. In the group who stated consumption of non food substances (pica) during their pregnancy gestational age, birth weight, length and head circumferences of neonates were slightly lower than those of without pica, but analysis of data showed there was no significant difference among them. Our finding supported by Rainville [13] study, that reported the pica practices is not associated with pregnancy outcome.

\section{Conclusions}

As the findings show the pica practices are associated with significantly lower maternal hemoglobin levels at delivery but it isn't associated with pregnancy outcome. Dietitian should ask pregnant women with anemia about pica and should counsel pregnant women who report pica.

Pica diagnosis during pregnancy is inexpensive and should be included in prenatal care; its early diagnosis would contribute to the identification of pregnant women who could be at increased risk for iron deficiency. In addition, it is necessary to implement strategies as regards both the evaluation and the nutritional education. 


\section{Conflict of Interest and Funding}

The current research is an academic research and all expenses are self-financing. No conflict of interest exists for any author.

\section{Acknowledgements}

We appreciate the administrators of health care centers, for their support and cooperation. Cooperation of the staff in selected of health care centers is highly acknowledged. We would like to thank the laboratory experts of Imam Reza Hospital and other colleagues who have contributed to this research. We are sincerely indebted to all the participants who made this study possible.

\section{References}

[1] Horner, R.D., Lackey, C.J., Kolasa, K. and Warren K. (1991) Pica Practices of Pregnant Women. Journal of the American Dietetic Association, 91, 34-38.

[2] Smulian, J.C., Motivala, S. and Sigman, R.K. (1995) Pica in Rural Obstetric Population. Southern Medical Journal, 88, 1236-1240. http://search.ebscohost.com http://dx.doi.org/10.1097/00007611-199512000-00010

[3] Edward, C.H., Johnson, A.A., Knight, E.M., Oyemade, U.J., Cole, O.J., Westney, O.E., Jones, S., Laryea, H. and Westney, L.S. (1994) Pica in an Urban Environment. Journal of Nutrition, 124, 954S-962S. www.ncbi.nlm.nih.gov/pubmed/8201446

[4] Faustina, O., Twumasi, M.P., Amenawonyo, K.X., Larbie, C., Asomaning, K. and Baffo, J. (2010) Pica Practice among Pregnant Women in the Kumasi Metropolis of Ghana. International Health, 2, 282-286. http://dx.doi.org/10.1016/j.inhe.2010.09.004

[5] Simpson, E., Mull, J.D., Longley, E. and East, J. (2000) Pica during Pregnancy in Low-Income Women Born in Mexico. Western Journal of Medicine, 173, 20-24. http://dx.doi.org/10.1136/ewjm.173.1.20

[6] Pope, J.F., Skinner, J.D. and Carruth, B.R. (1992) Craving and Aversions of Pregnant Adolescents. Journal of the American Dietetic Association, 92, 1479-1482. www.ncbi.nlm.nih.gov/pubmed/1452960

[7] Fairburn, C.G., Stein, A. and Jones, R. (1992) Eating Habits and Eating Disorders during Pregnancy. Psychosomatic Medicine, 54, 665-672. www.ncbi.nlm.nih.gov/pubmed/1454960 http://dx.doi.org/10.1097/00006842-199211000-00006

[8] Corbett, R.W., Ryan, C. and Weinrich, S.P. (2003) Pica in Pregnancy: Does It Affect Pregnancy Outcomes? American Journal of Maternal-Child Nursing, 28, 183-189. www.ncbi.nlm.nih.gov/pubmed/12771697 http://dx.doi.org/10.1097/00005721-200305000-00009

[9] Lopez, L., Soler, C.R.O. and Portela, M.L.D. (2004) Pica during Pregnancy: A Frequently Underestimated Problem. Archivos Latinoamericanos de Nutricion, 54, 17-24. www.ncbi.nlm.nih.gov/pubmed/15332352

[10] Mortazavi, Z. and Mohammadi, M. (2010) Prevalence of Pica in Pregnant Women Referred to Health Care Centers in Zahedan, Iran (2002-2003). African Journal of Food Science, 4, 642-645. www.academicjournals.org/.../54412FC26078

[11] Khoushabi, F. and Saraswathi, G. (2010) Impact of Nutritional Status on Birth Weight of Neonates in Zahedan City, Iran. Nutrition Research and Practice, 4, 339-344. www.ncbi.nlm.nih.gov/pubmed/20827351 http://dx.doi.org/10.4162/nrp.2010.4.4.339

[12] Jelliffee, D.B. (1966) The Assessment of the Nutritional Status of Community. World Health Organization, Geneva. http://www.who.int/iris/handle/10665/41780

[13] Rainville, A.J. (1998) Pica Practices of Pregnant Women Are Associated with Lower Maternal Hemoglobin Level at Delivery. Journal of the American Dietetic Association, 98, 293-296. www.ncbi.nlm.nih.gov/pubmed/9508011 http://dx.doi.org/10.1016/S0002-8223(98)00069-8

[14] Cooksey, N.R. (1995) Pica and Olfactory Craving of Pregnancy: How Deep Are the Secrets? Birth, 22, 129-137. www.ncbi.nlm.nih.gov/pubmed/7575860 http://dx.doi.org/10.1111/j.1523-536X.1995.tb00688.x

[15] Lopez, L.B., Langini, S.H. and Pita de Portela, M.L. (2007) Maternal Iron Status and Neonatal Outcomes in Women with Pica during Pregnancy. International Journal of Gynecology \& Obstetrics, 98, 151-152.

www.ncbi.nlm.nih.gov/pubmed/17572424

http://dx.doi.org/10.1016/j.ijgo.2007.03.038 
[16] Nyaruhucha, C.N. (2009) Food Cravings, Aversions and Pica among Pregnant Women in Dar es Salaam, Tanzania. Tanzania Journal of Health Research, 11, 29-34. www.ncbi.nlm.nih.gov/pubmed/19445102

[17] Kettaneh, A., Eclache, V., Fain, O., Sontag, C., Uzan, U., Carbillon, L., Stirnemann, J. and Thomas, M. (2005) Pica and Food Craving in Patients with Iron-Deficiency Anemia: A Case-Control Study in France. American Journal of Medicine, 118, 185-188. www.ncbi.nlm.nih.gov/pubmed/15694906 http://dx.doi.org/10.1016/j.amjmed.2004.07.050 
Scientific Research Publishing (SCIRP) is one of the largest Open Access journal publishers. It is currently publishing more than 200 open access, online, peer-reviewed journals covering a wide range of academic disciplines. SCIRP serves the worldwide academic communities and contributes to the progress and application of science with its publication.

Other selected journals from SCIRP are listed as below. Submit your manuscript to us via either submit@scirp.org or Online Submission Portal.
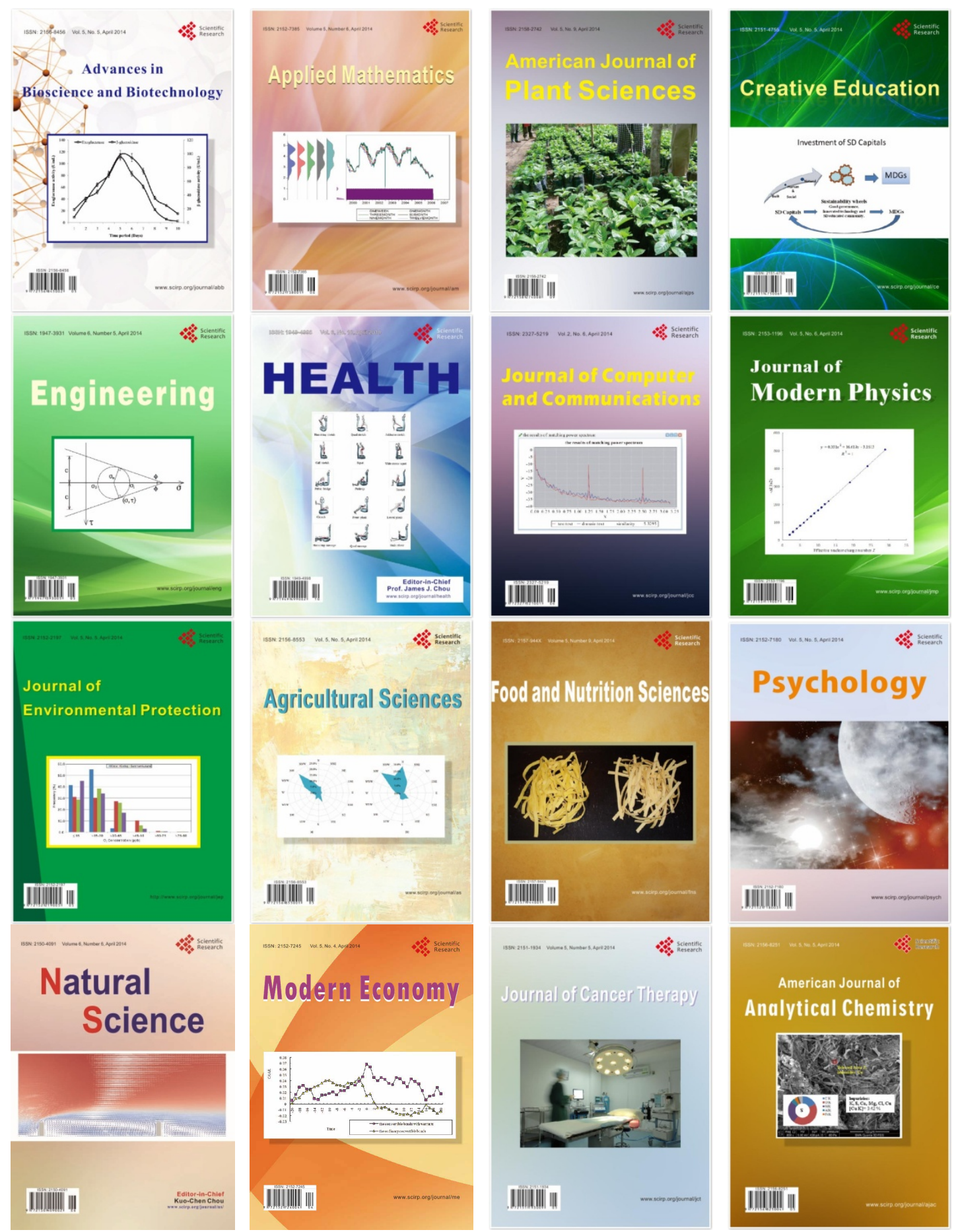